\title{
Histopathological spectrum of central nervous system lesions
}

\author{
Joshi H. ${ }^{1}$, Awasthi S. ${ }^{2}$, Dutta S. ${ }^{3}$, Bhardwaj R. ${ }^{4}$ \\ ${ }^{1}$ Dr. Himanshu Joshi, Assistant Professor, ${ }^{2}$ Dr. Seema Awasthi, Professor, ${ }^{3}$ Dr. Shyamoli Dutta, HOD \& Professor; ${ }^{1,2,3}$ Authors \\ are affiliated with the Department of Pathology, TMMC \& RC, Moradabad, Uttar Pradesh, India. ${ }^{4}$ Dr. Rashmi Bhardwaj, \\ Assistant Professor, Department of Anatomy, TMMC \& RC, Moradabad, Uttar Pradesh, India.
}

Corresponding Author: Dr. Rashmi Bhardwaj, Assistant Professor, Anatomy Department, TMMC \& RC, Moradabad, Uttar Pradesh, India. E-mail ID: rashmi.uks1210@gmail.com

\begin{abstract}
Introduction: Central nervous system (CNS) neoplasms, in India, constitute $1.9 \%$ of all cancers and in U.S. adults - $2 \%$ of all cancers. Many of the non-neoplastic CNS lesions can clinically \& radiologically simulate brain tumours. In such cases, histopathological examination (HPE) can be helpful in differentiating between neoplastic and non-neoplastic etiologies. Materials and Methods: This retrospective descriptive study of histopathological analysis of brain tumours was carried out in TMMC\&RC, Department of Pathology from January 2015 to December 2018. The biopsies were processed by routine histological techniques and H\&E stained sections were analyzed. Special stains and IHC were performed wherever appropriate. The diagnosed brain tumours were classified according to WHO 2016 classification system. Results: A total of 96 CNS biopsies were studied. The neoplasms constituted 62 (64.6\%) cases, which included 60 (96.8\%) primary, 1 (1.6\%) metastatic and 1 miscellaneous lesion (1.6\%). The 3 most common primary tumours were Astrocytic tumours, Schwannomas and Meningiomas. About 34(35.4\%) cases were non neoplastic out of which the 2 most common lesions were: Cystic Lesions and non-specific inflammation. Patients' age ranged from 5 days to 80 years. The ratio of number of male and female patients was 1:1.67. IHC for Glial Fibrillary Acidic Protein (GFAP) was positive in astrocytomas and mixed neuronal-glial tumours. Conclusion: The present study provides information regarding the spectrum and frequency of various CNS lesions in our area and concludes that histological examination of biopsies is gold standard for accurate diagnosis of various lesions of CNS when coupled with radiological and clinical data.
\end{abstract}

Keywords: Astrocytomas, CNS, Meningiomas.

\section{Introduction}

In terms of disease burden, 2016 data shows that there were $3,30,000$ new cases of CNS cancer with 2,27,000 deaths globally. Considering the age-standardised incidence rates for CNS cancers, these rates increased globally by $17.3 \%$ between 1990 and 2016. The region with the maximum number of new cases of CNS cancer for both sexes in 2016 was East Asia, followed in order by western Europe, and then south Asia. The top 3 countries having the highest number of new cases of CNS tumours were China, USA, and India [1].

The incidence rates of brain tumours between countries worldwide have shown almost threefold differences; with differences also seen between different ethnic groups within same country. Added to this complexity is the fact that the predominant CNS tumours are also different amongst adults and children Developed countries seems to have the highest rates of brain tumours which may in fact be the result of

Manuscript received: $14^{\text {th }}$ October 2019

Reviewed: $24^{\text {th }}$ October 2019

Author Corrected: $30^{\text {th }}$ October 2019

Accepted for Publication: $5^{\text {th }}$ November 2019 better registration systems which include benign tumours. The incidence of brain tumours rises with increasing age from 30 years old onwards, showing a similar trend with virtually all other adult cancers. The risk factors for neurocarcinogenesis is a combination of genetic predisposition with many environmental factors, the most well-established environmental risk factor being exposure to high doses of ionising radiation. Current thinking suggests that brain tumours develop as a consequence of accumulated genetic alterations in combination with many externally acting agents-chemical, physical or biological — that damage DNA $[2,3]$.

An understanding of the epidemiology is required which may facilitate early detection and treatment of CNS tumours. Patients having CNS neoplasms present clinically in a fairly characteristic manner with majority of them presenting with headache, vomiting and/or seizures. Diagnostic challenges because of atypical presentation, requires advanced neuro-radiological procedures such as Computed Tomography scans and/or Magnetic Resonance

Pathology Update: Tropical Journal of Pathology \& Microbiology Available online at: www.medresearch.in 844 | P a g e 
Imaging scans, to localize it $[4,5,6]$. Earlier brain tumours in India were thought to be uncommon, but over time and with advances in neuroimaging techniques over past few decades, it has become obvious that brain tumours in our country are as common as elsewhere in the world [6].

In developing countries like India, newly diagnosed cases are not routinely registered with local cancer registries. This causes underestimation of such cases and data.

Hospital-based Prevalence data is therefore the basis to estimate this disease load.

This study aims to provide frequency of CNS tumours in our tertiary care setup and compare the frequency of these CNS tumours and lesions with published literature in India \& worldwide.

\section{Materials \& Methods}

Setting: The Department of Pathology, Teerthanker Mahaveer Medical College and Research Centre, Moradabad, India.

Study design: Retrospective study.

Period of data collection: January 2015 and December 2018.

\section{Results}

Out of total 96 cases, 62 were neoplastic lesions and 34 were non - neoplastic lesions. The ratio of number of Male ( $\mathrm{n}=60)$ and female $(n=36)$ patients was $(60 / 36)$ 1.67:1 (Figure 1). Out of total 60 biopsies from male patients, 39 turned out to be neoplastic and 21 were non-neoplastic. Of the total 36 biopsies from female patients, 23 turned out to be neoplastic and 13 were nonneoplastic (Figure 2).
Sample size: 96 CNS lesions biopsies.

Inclusion criteria: All CNS biopsies received in the department of pathology during the study period.

Exclusion criteria: Inadequate biopsies and poorly preserved tissue specimens were excluded from study.

Ethical consideration \& permission: The present study was conducted after informed written consent being obtained from all the patients who underwent surgery.

Data analysis: - Data was compiled in MS Excel, checked for its correctness and then analyzed using online statistical calculator.

Method: Biopsies of CNS lesions were preserved in $10 \%$ formalin, followed by fixation for 24 hours. Haematoxylin and Eosin stained sections of these CNS lesions were obtained by routine processing and paraffin embedding. Special stains supplemented by IHC, wherever required, were employed.

Clinical history of all cases was collected in a pretested proforma meeting the objectives of the study. Diagnosis is made in accordance with the latest WHO 2016 classification and diagnostic criteria for CNS neoplasms [7].

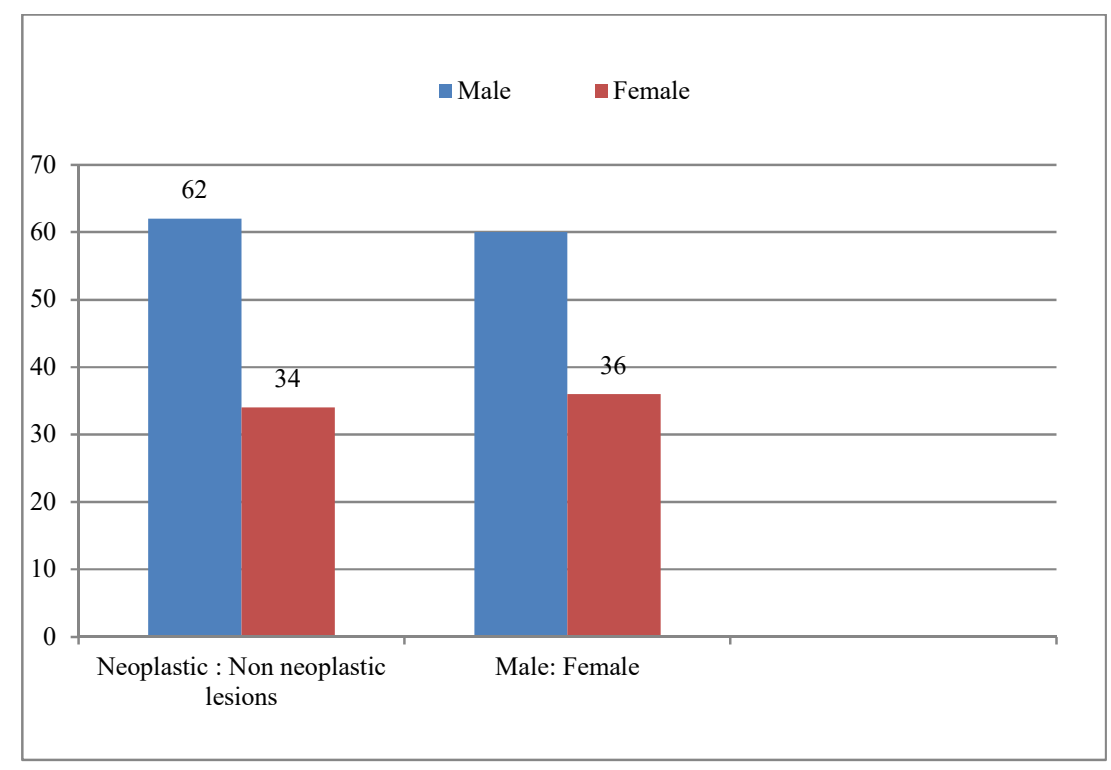

Fig-1: The ratio of number of male and female patients. 


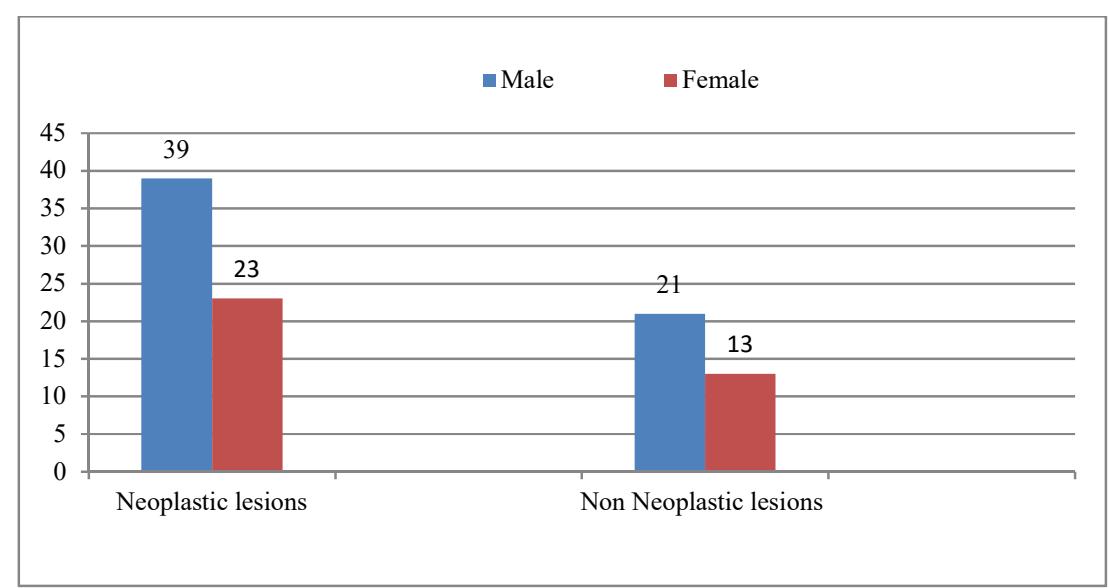

Fig-2: Distribution of biopsies in male and female patients.

Headache, vomiting and seizures were the most frequent presenting symptoms (headache being the most common) of patients and radiological examination showed SOLs (space occupying lesions) in most of the cases. The neoplastic lesions (39 cases were male and 23 cases were female) comprised of 62/96 (64.6\%) cases, which included $60(96.8 \%)$ primary, $1(1.6 \%)$ metastatic lesion and 1 miscellaneous lesion (1.6\%).

Among primary CNS tumours, majority cases were Astrocytic tumours $(n=17)$, followed by Schwannomas ( $n=14)$ and Meningiomas $(\mathrm{n}=12)$. The distribution of various other neoplastic lesions is as shown below.

Table-1: Distribution and frequency of neoplastic lesions.

\begin{tabular}{|c|c|c|c|}
\hline $\begin{array}{c}\text { Diffuse astrocytic and } \\
\text { oligodendroglial tumours }\end{array}$ & $\begin{array}{c}\text { 1) Astrocytic tumors }=17 \\
\text { 2) Oligodendroglial tumors }=1\end{array}$ & Embryonal tumors & 0 \\
\hline $\begin{array}{c}\text { Neuronal and mixed } \\
\text { neuronal-glial tumours }\end{array}$ & 2 & $\begin{array}{c}\text { Tumors of uncertain } \\
\text { histogenesis }\end{array}$ & Hemangioblastoma $=1$ \\
\hline Ependymal tumors & 4 & $\begin{array}{c}\text { Mesenchymal non- } \\
\text { meningothelial tumors }\end{array}$ & $\begin{array}{l}\text { 1) Lipoma, }=3 \\
\text { 2) Hemangiomas }=2\end{array}$ \\
\hline Tumors of meninges & Meningiomas $=12$ & Tumors of sellar region & Craniopharyngioma $=1$ \\
\hline $\begin{array}{c}\text { Tumors of cranial \& } \\
\text { paraspinal nerves }\end{array}$ & $\begin{array}{c}\text { 1) Neurofibroma }=0 \\
\text { 2) Schwannomas }=14\end{array}$ & Metastatic tumors & 1 \\
\hline Choroid plexus tumors & 1 & Tumours of pineal region & 2 \\
\hline & & Miscellaneous & 1 \\
\hline
\end{tabular}

Out of total of 96 cases, 34 (35.4\%) cases were non-neoplastic. Majority cases were showing Abscess and non-specific inflammation $(n=8,23.5 \%)$, followed by cystic lesions $(n=7,20.5 \%)$. The distribution of various other non-neoplastic lesions is as tabulated below.

Table-2: Distribution and frequency of various non-neoplastic lesions.

\begin{tabular}{|l|l|l|l|}
\hline $\begin{array}{l}\text { Developmental } \\
\text { malformations }\end{array}$ & $\begin{array}{l}\text { Meningomyelocoele-3 } \\
\text { Meningocoele-2 } \\
\text { Rachischisis-1 }\end{array}$ & Infectious lesions & $\begin{array}{l}\text { Amoebic brain abscess-1 } \\
\text { Neurocysticercosis-1 } \\
\text { Hydatid cyst-1 }\end{array}$ \\
\hline Granulomatous lesions & 6 & $\begin{array}{l}\text { Abscess and non-specific } \\
\text { inflammation }\end{array}$ & 8 \\
\hline Cystic lesions & $\begin{array}{l}\text { Hematoma } \\
\text { Epidermoid cyst-3 } \\
\text { Arachnoid cyst-2 } \\
\text { Sebaceous cyst-1 }\end{array}$ & & 4 \\
\hline & & & Total=34 \\
\hline
\end{tabular}




\section{Discussion}

The pathogenesis of spontaneously occurring CNS neoplasms in humans is a combination of genetic and environmental factors. CNS neoplasms associated with AIDS namely CNS lymphoma, has recently shown an increased trend due to increase in number of AIDS cases.

A variety of tumours occurs in CNS, but still accounts for less than $2 \%$ of all malignancies. But because of their location and mass effects, they generally have a poor prognosis $[8,9]$.

The present study shows that 96 cases of CNS lesions share many of the features common with other published series.

The most common presenting symptom in present series was headache which is supported by the findings of many other studies as well. $[6,12]$. The frequency of cystic lesions of CNS in the present study $(n=7 ; 20.5 \%)$ compared well with other studies $[10,11,12]$, which also revealed epidermoid cyst to be the predominant cystic lesion. The male to female ratio of 1.69:1 for malignant lesions and 1.61:1 for non-neoplastic lesions in present study of 96 biopsies show a pattern of male predominance. Patients' age ranged from 5 days to 80 years which is different from studies conducted by Mohammad Sajjad et al, Ghanghoria et al, their studies showed age range of 09-70, 1-85 years, respectively $[4,13]$.

The results of present study as compared to various other studies is as shown below.

Table-3: Present study compared with similar other studies.

\begin{tabular}{|l|c|c|c|c|c|c|}
\hline Histological Type & & & & & & \\
\hline & Present Study & Aryal G [14] & $\begin{array}{c}\text { Katsura et al } \\
{[15]}\end{array}$ & $\begin{array}{c}\text { Verma et } \\
\text { al [16] }\end{array}$ & $\begin{array}{c}\text { Monga K } \\
\text { et al, [17] }\end{array}$ & $\begin{array}{c}\text { Hema NA } \\
\text { et al [18] }\end{array}$ \\
\hline Neuroepithelial tumours & $33(53.2 \%)$ & $38.6 \%$ & $31.68 \%$ & $61.6 \%$ & $51.42 \%$ & $56.3 \%$ \\
\hline Meningeal tumours & $12(19.4 \%)$ & $14 \%$ & $15.71 \%$ & $14.8 \%$ & $17.14 \%$ & $12.5 \%$ \\
\hline $\begin{array}{l}\text { Tumours of cranial \& } \\
\text { paraspinal nerves }\end{array}$ & $14(22.6 \%)$ & $5.2 \%$ & $11.85 \%$ & $4.95 \%$ & $4.28 \%$ & $16.6 \%$ \\
\hline Pituitary tumours & $2(3.2 \%)$ & $5.2 \%$ & $9.44 \%$ & $7.6 \%$ & $10 \%$ & $2.1 \%$ \\
\hline Metastatic tumours & $1(1.6 \%)$ & $14 \%$ & $4.28 \%$ & $3.89 \%$ & $1.42 \%$ & $0 \%$ \\
\hline
\end{tabular}

In the present study, tumours of the neuroepithelial origin $(n=33,53.2 \%)$ represented maximum number of cases of intracranial neoplasms amongst all primary CNS tumours - in close agreement with observations made in various other studies by Verma et al, Monga $\mathrm{K}$ et al, Hema NA et al and Anand et al. [16,17,18,19].

The studies by Katsura et al (31.68\%), Aryal G (38.6\%) and Chawla et al (38.7\%)., showed lower relative frequencies $[14,15,20]$. Ependymoma constituted $6.4 \%$ of all CNS neoplasms which is comparable to $4.0 \%$ and $4.7 \%$ incidence reported by Masoodi et al and Mollah et al $[5,21]$. The relative frequency of $19.4 \%$ of meningiomas in the present study is in close agreement with other studies which reported 18\% (Chawla et al.,), 17.14\% ( Monga K et al.), 15.17\% (Katsura et al) and 11\% (Kalyani D et al.,) [12], $[15,17,20]$. However, meningiomas constituted the predominant subgroup in studies by Ghanghoria $\mathrm{S}$ et al in a similar way in studies done by Surawicz et al, in USA and Lee et al in Korea $[4,22,23]$.

The relative frequency of pituitary tumours in the present study was 3.2\%, in close agreement with study by Hema NA et, which showed a relative frequency of $2.1 \%$ [18]. The relative frequency of tumours of cranial \& paraspinal nerves $22.6 \%$ is a bit higher in the present study group as compared with other studies. This difference in relative frequencies of different CNS lesions in the present study with other similar published studies may be attributed to differences in sample size, population and regional characteristics. Cystic lesions, cerebral abscess and Non-specific inflammations were the predominant non-neoplastic lesions of present study.

\section{Limitation of the present study}

1. Few IHC markers like TP53, INI1, MIB 1, CD 1a, CEA, TTF1 could not be employed at our centre, and these cases were referred to higher centres for these specific marker studies.

2. The specimens for this study were obtained from a restricted geographical population from regional area of Moradabad.

Pathology Update: Tropical Journal of Pathology \& Microbiology Available online at: www.medresearch.in 847 | P a g e 
Importance of the present study: The present study has highlighted the relative frequency of different CNS lesions in Moradabad region. In developing countries like India, newly diagnosed cases are not routinely registered with local cancer registries which causes underestimation of such cases and data. Such Hospital-based Prevalence data and studies is therefore the basis to estimate this disease load. Primary CNS tumours and lesions are heterogeneous entities frequently encountered in clinical practice.

Many studies and reports have suggested incidence and pattern of intracranial neoplasms as subjects of considerable geographic and racial variation [24]. Keeping track of the change in trends of various CNS lesions is essential so that improvements in clinical practices can be employed in a timely fashion [25].

\section{Conclusions}

Histopathological study is the gold standard and along with clinico-radiological correlation with use of IHC, wherever required, plays important role in arriving at a definitive diagnosis in neuro-pathology.

\section{What this study adds to the existing knowledge?}

The utility of IHC has been emphasized in the present study. GFAP which is a sensitive and specific marker for glial differentiation and establishing the origin of astrocytic tumours, was employed wherever required.

This study thus shows that with the basic IHC panel and $\mathrm{H} \& \mathrm{E}$ stained section examination, diagnosis is possible in most cases. Additional and advanced IHC markers are needed in only limited number of cases.

\section{Author's contribution}

Dr. Himanshu Joshi, Dr. Seema Awasthi, Dr. Shyamoli Dutta: Diagnosis.

Dr. Rashmi Bhardwaj: Diagnosis, data analysis and manuscript preparation.

Funding: No funding sources

Conflict of interest: None declared

Ethical Approval: This study was approved by the Institutional Ethics Committee

\section{Acknowledgement}

Authors would like to thank Dr. Vivek Singh and Dr. Rashmi Chauhan for their help in IHC work up and diagnosis.

\section{References}

1. Global Burden of Disease Cancer Collaboration. Global, Regional, and National Cancer Incidence, Mortality, Years of Life Lost, Years Lived with Disability, and DisabilityAdjusted Life-years for 32 Cancer Groups, 1990 to 2015: A Systematic Analysis for the Global Burden of Disease Study. JAMA Oncol. 2017;3(4): 524-548. doi:10.1001/ jamaoncol. 2016.5688.
2. Wrensch M, Minn Y, Chew T, Bondy M, Berger MS. Epidemiology of primary brain tumours: current concepts and review of the literature. Neuro-oncology. 2002; 4(4): 278-299. doi:10.1093/neuonc/4.4.278.

3. Davis FG, McCarthy BJ. Current epidemiological trends and surveillance issues in brain tumours. Expert Rev AnticancerTher2001;1(3):395-401.doi:10.1586/14737140. 1.3.395.

4. Ghanghoria S, Mehar R, Kulkarni CV, Mittal M, Yadav A, Patidar H. Retrospective histological analysis of CNS tumours-A 5-year study. Int J Med Sci Public Health. 2014; 10 (3): 1205-1207. doi: 10.5455/ ijmsph. 2014. 0807 20141.

5. Mollah N, Baki A, Afzal N, Hossen A. Clinical and pathological characteristics of brain tumor. Bangabandhu Sheikh Mujib Medical University J. 2010;3(2):68-71. doi:https://doi.org/10.3329/bsmmuj.v3i2.7054.

6. Rathod V, Bhole A, Chauhan M, Ramteke H, Wani B. Study of clinico-radiological and clinico-pathological correlation of intracranial space occupying lesion at rural center. Int J Neurosurg. 2009;7(1).

7. Komori T. The 2016 WHO Classification of Tumours of the Central Nervous System: The Major Points of Revision. Neurol Med Chir (Tokyo). 2017;57(7):301-311. doi:10.2176/nmc.ra.2017-0010

8. Yeole BB. Trends in the Brain cancer incidence in India Asian Pac J Cancer Prev 2008;9(2):267-270.

9. Madabhushi V, Venkata RI, Garikaparthi S, Kakarala SV, Duttaluru SS. Role of immunohistochemistry in diagnosis of brain tumours: A single institutional experience. J NTR Univ Health Sci 2015; 4:103-111. doi: $10.4103 / 2277-8632.154262$.

10. Butt ME, Khan SA, Chaudrhy NA and Qureshi GR. Intracranial Space occupying lesions - A morphological analysis. Biomedica. 2005;21:31-35. 
11. Kothari F, Shah A. Prospective study of intra cranial tumour. SEAJCRR. 2014;3(5):918-932.

12. Kalyani D, Rajyalakshmi S, Sravan Kumar O. Clinicopathological study of posterior fossa intracranial lesions. J Med Allied Sci. 2014;4(2):62-68.

13. Sajjad M, Shah H, Khan ZASU. Histopathological pattern of intracranial tumors in a tertiary care hospital of Peshawar, Pakistan. J SZMC. 2015;7(1):909-912.

14. Aryal G. Histopathological pattern of central nervous system tumor: A three-year retrospective study. J Pathol Nepal 2011;1:22-25.

15. Katsura S, Suzui J, Wada T. A statistical study of brain tumours in the neurosurgical clinics in japan. J Neurosurg. 1959;16(5):570-580. doi:10.3171/jns.1959.16.5.0570

16. Verma RN, Subramanyam CSV, Banerjee AK. Intracranial neoplasms- pathological review of 283 cases. Indian J Pathol Microbiol. 1983;26(4):289-297.

17. Monga K, Gupta VK, Gupta S, Marwah K. Clinicopathological study and epidemiological spectrum of brain tumours in Rajasthan. Indian J Basic App Med Res. 2015; 5(1):728-734.

18. Hema NA, Ravindra RS, Karnappa AS. Morphological Patterns of Intracranial Lesions in a Tertiary Care Hospital in North Karnataka: A Clinicopathological and Immunohistochemical Study. J Clin Diagn Res. 2016;10 (8): EC01EC05. doi: 10.7860/JCDR/2016/19101.8237
19. Anand A, Sonawane B, Titare P, Rathod P. Computed tomography evaluation of Intracranial space occupying lesions in adults. Int J Sci Study. 2014;2(9):47-52.

20. Chawla N, Kataria SP, Malik S, Sharma N, Kumar S. Histopathological spectrum of cns tumours in a tertiary care referral centre-A one-year study. Int J Basic App Med Sci. 2014;4(2):141-145.

21. Masoodi T, Gupta RK, Singh JP, Khajuria A. Pattern of central nervous system neoplasms: a study of 106 cases. JKPractitioner. 2012;17(4):42-46.

22. Surawicz TS, Davis F, Freels S, Laws ER, Menck HR. Brain tumor survival: Results from the National Cancer Data Base. J Neuro-Oncology. 1998;40(2):151-160. doi: 10. 1023/a:1006091608586.

23. Lee $\mathrm{CH}$, Jung $\mathrm{KW}$, Yoo $\mathrm{H}$, Park $\mathrm{S}$, Lee $\mathrm{SH}$. Epidemiology of primary brain and central nervous system tumors in Korea. J Korean Neurosurg Soc. 2010; 48(2):145152. doi:10.3340/jkns.2010.48.2.145.

24. Jamjoom AB. Patterns of intracranial space occupying lesions: the experience at King Khalid Hospital. Ann Saudi Med.1989; 9(1): 166-178. doi: https://doi.org/10.5144/ 0256-4947.1989.3.

25. Ayaz B, lodhi FR, Hassan M. Central nervous system tumours: a hospital based analysis. Pak Armed Forces Med J. 2011; 61(1):61-64.

\section{How to cite this article?}

Joshi H, Awasthi S, Dutta S, Bhardwaj R. Histopathological spectrum of central nervous system lesions. Trop J Path Micro 2019;5(11):844-849.doi:10.17511/jopm.2019.i11.02 